\title{
Quaderni
}

QUADERNI Communication, technologies, pouvoir

102 | Hiver 2020-2021

Politique(s) des dystopies

\section{Éditorial : Chaque jour, la fin du monde}

\section{Emmanuel Taïeb et Étienne Candel}

\section{(2) OpenEdition}

Journals

Édition électronique

URL : http://journals.openedition.org/quaderni/1857

DOI : 10.4000/quaderni.1857

ISSN : 2105-2956

\section{Éditeur}

Les éditions de la Maison des sciences de l'Homme

\section{Édition imprimée}

Date de publication : 5 janvier 2021

Pagination : 9-11

\section{Référence électronique}

Emmanuel Taïeb et Étienne Candel, «Éditorial : Chaque jour, la fin du monde », Quaderni [En ligne], 102 | Hiver 2020-2021, mis en ligne le 05 janvier 2021, consulté le 29 janvier 2021. URL : http:// journals.openedition.org/quaderni/1857 ; DOI : https://doi.org/10.4000/quaderni.1857 


\section{Éditorial: \\ Chaque jour, \\ la fin du monde}

\section{Emmanuel Taïeb}

Sciences Po Lyon (Triangle)

\section{Étienne Candel}

Université de Paris (CERLIS) 
Programmé bien avant que le Covid-19 prenne son envol mondial, ce dossier consacré aux dystopies nous saisit dans un moment d'inquiétude et d'incertitude collectives, et l'éclaire dans le détour par la fiction (mais pas seulement). Car c'est bien la fiction qui a souvent été convoquée pour essayer de penser la crise sanitaire, quand les routines politiques habituelles ne semblaient plus s'activer, ni aucune jurisprudence s'appliquer (la grippe de Hong Kong de 1968 était mal connue des politiques, et l'épidémie de grippe espagnole avait plus d'un siècle). Sur les réseaux sociaux numériques, on a vu ainsi circuler un "mème" proposant d'apposer sur sa fenêtre un autocollant transparent indiquant "Directed by David Lynch", pour redonner du "sens", même dérangeant, à un monde social qui paraissait ne plus en avoir.

Tout le cinéma de David Cronenberg aurait pu aussi être convoqué, comme le film Contagion de Steven Soderbergh (2011), Phénomènes de M. Night Shyamalan (2008), ou 28 jours plus tard, de Danny Boyle (2003), ou encore la série The Walking Dead (depuis 2010). Car les fictions dystopiques ont anticipé depuis longtemps les avenirs sombres possibles de l'humanité. Leur prolifération a créé une étrange familiarité avec la fin du monde, comme si chaque jour une nouvelle catastrophe devait s'abattre sur l'humanité et la décimer. Comme si chaque jour en temps d'épidémie bien réelle, le destin des malades et des confinés était d'expérimenter sinon une fin avérée du moins une catastrophe virale; et cette fois, c'est Un jour sans fin, d'Harold Ramis (1993) qui pouvait servir de boussole dans la similitude des journées de confinement.

$\mathrm{Si}$, comme le disait Norbert Elias, la prévision se confond avec la civilisation, l'impossibilité de se projeter fait craindre le retour de la barbarie. Or, précisément, penser le moment dystopique permet de la conjurer, car tout y est. Fin des ressources fossiles, changement climatique drastique (la climate fiction est devenue un genre en soi), "vengeance" de la nature, catastrophe nucléaire, invasion extraterrestre, pandémie incontrôlable, phénomène ou cataclysme inexplicable, les auteurs de science-fiction n'ont pas été à court d'hypothèses pour dépeindre les menaces. Au fil des époques, toutes les stratégies de survie possible de l'humanité ont été envisagées, la fiction formant alors un important réservoir d'idées et de propositions. L'évidence désormais de cette passion morose est en soi à interroger.

À ceci près que la dystopie ne se confond pas nécessairement avec le discours collapsologique et la thématisation de la fin du monde. Un simple décalage suffit, technique par exemple, pour qu'un univers d'inquiétante étrangeté se déploie. L'humanité y survit bien, mais radicalement ou légèrement transformée, dans l'oubli surtout de ce qui avait pu exister auparavant. C'est bien la peur de cette perte du monde commun, de l'humanité commune, qui motive la fiction; même si elle a pu déjà avoir lieu, en fait, des guerres mondiales à la Shoah. La fiction se donne comme lanceuse d'alerte, comme arme, pas seulement pour dire la fin, 
qui est trop massive et trop incertaine, mais pour préparer à tous les changements, et étrangement les pires. Montrer et raconter, pour éviter. Arme intellectuelle et politique consolatrice, qui refuse la démission, et entend servir peut-être un jour si elle est suffisamment propositionnelle. Si le scénario de la catastrophe est trop effrayant (pour être crédible), une "simple" dystopie suffira. Un monde habité mais inhabitable, dominé par la violence politique, l'écrasement économique, l'effacement du corps, ou le triomphe de valeurs anti-humanistes. Parfois dans un paradoxe saisissant, où les fictions lancent l'alerte sur des utopies sombres qu'elles mettent elles-mêmes en scène...

Le dossier de ce numéro, "Politique(s) des dystopies", entend analyser les formes fantasmées et fictionnelles du pessimisme, mais aussi enregistrer le désir inquiet que lui porte notre époque. 